\title{
MAPEAMENTO DE FRAGMENTOS FLORESTAIS COM MONODOMINÂNCIA DE AROEIRA A PARTIR DA CLASSIFICAÇÃO SUPERVISIONADA DE IMAGENS RAPIDEYE ${ }^{1}$
}

Felipe Pinho de Oliveira ${ }^{2}$, Elpídio Inácio Fernandes Filho ${ }^{3}$, Vicente Paulo Soares ${ }^{4}$ e Agostinho Lopes de Souza $^{4}$

\begin{abstract}
RESUMO - A espécie florestal Myracrodruon urundeuva (Fr. All.) figura desde 1992 na lista de espécies da flora brasileira ameaçadas de extinção e, contudo, manifesta comportamento monodominante em algumas regiões do Estado de Minas Gerais, sobretudo na região do Médio Rio Doce. Este trabalho teve por objetivo comparar métodos de classificação supervisionada de imagens Rapideye para mapeamento de fragmentos florestais monodominados por Myracrodruon urundeuva em Tumiritinga, MG. Foram avaliadas a classificação pelo algoritmo da Maximaverossimilhança (Maxver) e a classificação por Redes Neurais Artificiais (RNA). Foram testadas 19 combinações envolvendo diferentes bandas, componentes principais e o índice de vegetação da diferença normalizada para a classificação da imagem Rapideye. O treinamento da rede foi realizado variando-se a taxa de aprendizado, o número de interações e o número de neurônios na camada interna. A avaliação dos mapas temáticos produzidos foi realizada através dos índices Kappa e Kappa condicional para a classe de uso do solo "aroeira" e pela análise das Matrizes de Confusão. O método que apresentou melhor desempenho foi a classificação de todas as bandas da imagem Rapideye pelo algoritmo Maxver, apresentando coeficientes Kappa 80 e Kappa condicional 90 . O mapa temático gerado teve exatidão do usuário igual a 93\% e exatidão do produtor igual a 90\%, sendo as maiores confusões do classificador para a classe Aroeira Monodominante acometidas entre as classes Mata Nativa e Pasto Manejado. Da imagem temática produzida, extraiu-se a informação de que 22\% do Município de Tumiritinga se encontrava sob ocupação da aroeira em monodominância. A análise do uso e cobertura do solo no município não retrata, na região de estudo, o quadro anunciado de espécie ameaçada de extinção, no qual $M$. urundeuva se encontra.
\end{abstract}

Palavras-chave: Myracrodruon urundeuva, Monodominância, Classificação supervisionada de imagens.

\section{MAPPING OF FOREST FRAGMENTS WITH MONO-DOMINANCE OF AROEIRA BY SUPERVISED CLASSIFICATION OF RAPIDEYE IMAGES}

\begin{abstract}
M. urundeuva (Fr. All.) is a tree currently listed as endangered species of Brazilian Flora since 1992. However, it manifests monodominance in some regions of Minas Gerais state, especially in middle Rio Doce. The objective of this work was to compare supervised methods of classification of Rapideye images for forest fragments monodominated by Myracrodruon urundeuva mapping, in Tumiritinga, MG. The maximum likelihood (Maxlike) and the artificial neural networks (ANN) classification were assessed. Nineteen combinations involving different bands, the principal components and the normalized difference vegetation index (NDVI) were tested for classification of Rapideye image. The neural network training was conducted by varying the learning rate, the number of interactions and the number of neurons in the hidden layer. The thematic maps were evaluated by Kappa and conditional Kappa index for "aroeira" soil use class and by the analysis of the Confusion Matrix. The best performance was achieved by the Maxever algorithm using all bands of Rapideye
\end{abstract}

\footnotetext{
${ }^{1}$ Recebido em 09.07.2012 aceito para publicação em 20.12.2012

${ }^{2}$ Programa de Pós-Graduação em Solos e Nutrição de Plantas pela Universidade Federal de Viçosa, UFV, Brasil. E-mail: $<$ pinhofelipe@ hotmail.com>.

${ }^{3}$ Departamento de Solos da Universidade Federal de Viçosa, UFV, Brasil. E-mail: <elpidio@ufv.br>.

${ }^{4}$ Departamento de Engenharia Florestal da Universidade Federal de Viçosa. E-mail:<alsouza@ gmail.com>e < vicentepsoares@gmail.com>.
} 
image, getting a Kappa index of 80 and conditional Kappa index of 90 . The thematic map presented user's accuracy equal to $93 \%$ and producer's accuracy equal to $90 \%$. The greatest errors of classification for "aroeira monominant" class were related to the "native forest" and "managed pasture" classes. The thematic map produced shows that $22 \%$ of the town is under occupation of M. urundeuva in monodominance and this specie is not endangered in Tumiritinga, Minas Gerais.

Keywords: Myracrodruon urundeuva. Mono-dominance. Supervised classification of images.

\section{INTRODUÇÃO}

O histórico de uso e ocupação do solo no médio rio Doce mineiro deflagrou processos degenerativos dos recursos naturais que implicaram problemas ambientais sociais e econômicos enfrentados até o momento(BARUQUI, 1982; FAVERO, 2001; VALENTE, 2005; VIEIRA, 2008.).

Valente (2005), caracterizando a intensidade de degradação do solo e da cobertura vegetal em uma região do médio rio Doce, discorreu sobre os raros remanescentes florestais que resistiram à ação antropogênica. Esse autor chamou a atenção para um fenômeno que vem ocorrendo na região do médio rio Doce, a expansão de fragmentos monodominados por aroeira (Myracrodruon urundeuva Fr. All.), espécie caducifólia que não raro ocupa toda a topossequência de determinados sítios.

Paralelo ao quadro de expansão de áreas monodominadas pela aroeira no médio rio Doce e em outras regiões do Estado de Minas Gerais, a espécie aparece na lista oficial da flora brasileira ameaçada de extinção na categoria "vulnerável” desde 1992 (BRASIL, 2008).

Analisando a contradição no enquadramento jurídico da espécie, Murta et al. (2010) sugeriram que a falta de conhecimento sobre esses fragmentos acarreta insegurança aos operadores do direito, no que tange à autorização de intervenção nesses ambientes, seja visando à recuperação de áreas degradadas ou ao manejo sustentável desses fragmentos.

Diante da necessidade de obtenção e processamento de informações atualizadas e detalhadas a respeito da distribuição espacial dos "aroeirais", a utilização de técnicas de classificação supervisionada de imagens, aliadas aos produtos do Sensoriamento Remoto, podem contribuir para o estudo de áreas monodominadas por aroeira, permitindo identificar, mensurar e monitorar esses povoamentos.

A classificação supervisionada de imagens orbitais é um método amplamente utilizado em estudos de mapeamento e avaliação das mudanças ocorridas no uso e ocupação do solo (KAVZOGLU; VIEIRA, 1998; FRANÇA, 2007; PRADO et al., 2009; HORNING et al., 2010).

Entre os métodos de classificação supervisionada de imagens, o algoritmo da máxima verossimilhança (Maxver) figura entre uma das metodologias mais aplicadas a estudos de caracterização, mensuração e monitoramento de áreas florestais e agrícolas (AMARAL et al., 2009; MOREIRA et al., 2010; RAMIREZ et al., 2010). Outra metodologia de classificação de imagens que merece destaque são as redes neurais artificiais (RNA). Segundo Kavzoglu e Vieira (1998), a capacidade de aprendizado, generalização e reconhecimento de padrões torna as redes neurais artificiais atrativas para a classificação supervisionada de dados do sensoriamento remoto.

Assim como os métodos de classificação de imagens, os sensores remotos evoluíram, principalmente, no que diz respeito às suas resoluções temporais, espectrais e espaciais. Nesse sentido, Schuster et al. (2010) avaliaram a resposta da banda espectral red edge $(0,68-0,73$ $\mu \mathrm{m})$, presente no sensor multiespectral do satélite Rapideye, para a classificação de uso do solo. Esses autores observaram melhora no resultado da classificação de florestas deciduais pelo algoritmo da máxima verossimilhança, ao utilizarem a referida banda do sensor.

Nesse contexto, este estudo teve por objetivo principal comparar métodos de classificação supervisionada de imagens Rapideye utilizando diferentes composições de bandas, componentes principais e índices de vegetação visando à otimização metodológica para mapeamento de fragmentos florestais monodominados por Myracrodruon urundeuva em Tumiritinga, MG.

\section{MATERIAL E MÉTODOS}

\subsection{Caracterização regional do local de estudo}

O estudo foi desenvolvido no Município de Tumiritinga, MG. A sede municipal está localizada no ponto de coordenadas $18^{\circ} 58^{\prime} 44^{\prime \prime}$ Sul e 41 ${ }^{\circ} 38^{\prime} 42^{\prime \prime}$ 'Oeste.

Revista Árvore, Viçosa-MG, v.37, n.1, p.151-161, 2013 
O município ocupa uma área de $500 \mathrm{~km}^{2}$ com uma população de 6.293 habitantes e pertence à mesorregião do Vale do Rio Doce, microrregião de Governador Valadares (IBGE, 2010). O município está inserido no domínio dos Argissolos Vermelhos Eutróficos, distribuídos desde o terço inferior até o topo dos morros. Entretanto, ocorrem Neossolos Flúvicos Eutróficos nas baixadas, e em alguns topos planos é comum a ocorrência de latossolos (BARUQUI, 1982).

As unidades geomorfológicas presentes são caracterizadas por dissecação fluvial atuante nas rochas predominantemente granito-gnáissicas do embasamento cristalino (BARUQUI, 1982). Pela classificação de Köppen, o clima predominante na região é o Aw (tropical úmido megatérmico), caracterizado por elevadas temperaturas e chuvas concentradas no verão, sendo a precipitação do mês mais seco inferior a $60 \mathrm{~mm}$. O balanço hídrico da região mostra acentuado déficit hídrico (VALENTE, 2005).

A vegetação original se insere na região fitoecológica da Floresta Estacional Semidecidual (VELOSO et al., 1991), inclusa no Bioma Floresta Atlântica. De acordo com levantamentos do Censo Agropecuário do IBGE (IBGE, 2006), a área municipal ocupada por matas e, ou, florestas naturais corresponde a $2 \%$ do município.

\subsection{Base de dados}

O uso do solo e os estágios fitofisionômicos dos "aroeirais" sofrem grandes transformações sazonais e, portanto, apresentam características espectrais diferenciadas ao longo do ano. Assim, para a escolha da data de aquisição das imagens, optou-se pelo período posterior às chuvas na região, garantindo a ausência de nuvens e o vigor da vegetação. O estudo foi realizado a partir de uma imagem Rapideye adquirida em 13/02/ 2010, com as devidas correções geométricas e recobrindo $100 \%$ do município.

Foram avaliadas 19 diferentes composições, envolvendo bandas multiespectrais, componentes principais e índices de vegetação (Tabela 1), a fim de avaliar qual a melhor combinação a ser utilizada na classificação da imagem Rapideye capaz de diferenciar áreas sob monodominância de aroeira das demais classes de uso do solo na região de estudo.

O NDVI foi calculado a partir da expressão:

$$
\mathrm{NDVI}=\frac{(\mathrm{NIV}-\mathrm{VIS})}{(\mathrm{NIV}+\mathrm{VIS})}
$$

em que NIV = reflectância da faixa de infravermelho (banda 5 - 0,76 a 0,85 $\mu \mathrm{m}$ ) e VIS = reflectância da faixa do visível (banda 3 - 0,63 a 0,67 $\mu \mathrm{m}$ ).

Para avaliar a influência da banda 4 (red edge) na separação de feições sob monodominância de aroeira (SCHUSTER et al., 2010), o NDVI foi também calculado de forma adaptada, utilizando a banda 3 (0,63 a 0,68 $\mu \mathrm{m})$ e a banda $4(0,69$ a 0,73), red-edge, em substituição à banda do infravermelho, sendo aqui tratado de NDVI_edge. Uma última composição avaliada envolveu todas as variáveis (bandas, componentes principais e índices de vegetação) utilizadas neste estudo.

\subsection{Seleção e validação das amostras de treinamento}

O treinamento dos algoritmos Maxver e RNA foi dividido em três etapas: definição das classes temáticas de uso do solo; coleta de amostras de treinamento e avaliação do grau de sobreposição das amostras de treinamento.

As classes temáticas para mapeamento foram definidas levando-se em consideração as formas predominantes de uso e ocupação do solo no município de estudo, as características espectrais dos alvos a mapear e a resolução espacial da imagem Rapideye. O território municipal foi intensamente percorrido, tendo suas feições de uso registradas por fotografias e pontos de controle terrestre coletados com aparelho GPS de navegação. Assim, foram definidas oito classes de uso/cobertura do solo: rio Doce (RD), aroeira monodominante (AM), mata nativa (MN), área urbana/ solo exposto arenoso (SE), solo exposto argiloso (SA), afloramento de rocha (AR), pasto manejado (PM) e pasto degradado (PD).

Neste trabalho, atenção especial foi dada à seleção e coleta de amostras de treinamento. De acordo com Congalton (1991) e Tso e Mather (2009), a definição do tamanho das amostras é importante para determinação da acurácia dos parâmetros estatísticos que descrevem as classes a serem obtidas. Esses autores afirmaram também que o número de amostras de treinamento está diretamente relacionado com o intervalo de confiança das estimativas de acurácia de uma classificação e com os parâmetros estatísticos estimados utilizados pelos algoritmos de classificação.

Revista Árvore, Viçosa-MG, v.37, n.1, p.151-161, 2013 
Para definição do número de amostras de treinamento, foi utilizada a recomendação de Congalton e Green (1999), extraindo-se no mínimo 75 amostras de treinamento por classe de uso do solo. Segundo McCoy (2005), para classes que apresentam maior variabilidade espectral é importante coletar maior número de amostras de treinamento. Assim, para as classes de uso AM e MN, foram coletadas, em média, 300 amostras de treinamento por classe.

Utilizaram-se polígonos de formas quadradas e retangulares para a extração das amostras de treinamento, como forma de evitar muitos vértices na amostra (CAMPBELL, 1987). O número de pixels em cada amostra de treinamento variou entre 9 e 12 (McCOY, 2005).

Para avaliar o grau de sobreposição de classes de uso nas amostras de treinamento, foi utilizado o índice de separação de classes Jefferyes-Matusita definido por:

$$
J M_{i j}=2 *\left(1-e^{-B i j}\right)
$$

em que $B_{i j}$ é a distância de Bhattacharyya calculada a partir da expressão:

$B_{i j}=\frac{1}{8}\left(M_{i}-M_{j}\right)^{T}\left(\frac{\Sigma_{i}+\Sigma_{j}}{2}\right)^{-1}\left(M_{i}-M_{j}\right)+\frac{1}{2}\left(\frac{\left|\frac{\Sigma_{i}+\Sigma_{j}}{2}\right|}{\sqrt{\left|\Sigma_{i}\right|\left|\Sigma_{j}\right|}}\right)$

em que $M_{i}$ e $M_{j}$ são os vetores das médias das classes i e j. Quanto maior o valor de $B$, maior a separabilidade das classes.
O valor de $J M$ é calculado por par de classes. O índice varia em uma escala de 0 a 2 . Se as classes $i$ e $j$ obtiveram um valor $J M$ de 2 , isso significa que as amostras são completamente distintas. De acordo Vieira (2000), valores superiores a 1,5 expressa ótima separabilidade entre classes para fim de classificação.

\subsection{Classificação supervisionada}

A classificação supervisionada da imagem Rapideye foi realizada através do algoritmo da máxima verossimilhança (Maxver) e através de redes neurais artificiais (RNAs). A classificação pelo Maxver foi implementada utilizando a interface do software ArcGis 10. Para o treinamento das arquiteturas das RNAs, utilizou-se a interface do software Idrisi Andes, módulo Multi-Layer Perceptron Classifier, que utiliza o algoritmo backpropagation para classificação das imagens.

As amostras de treinamento selecionadas na imagem das 19 composições envolvendo bandas multiespectrais, componentes principais e o NDVI serviram como base de entrada de dados para o treinamento das redes neurais.

Após a definição das combinações utilizadas para a classificação, estas foram reescalonadas para o intervalo de 0 a 1 para facilitar o processo de treinamento da rede e simplificar sua estrutura (CHAGAS, 2006).

O treinamento da rede foi realizado por tentativa e erro, variando-se a taxa de aprendizado, o número de interações e o número de neurônios na camada oculta (VIEIRA, 2000). O fator momento foi fixado em $0,5, \mathrm{o}$ número de camada oculta fixado em 1 e o número de neurônios na camada de saída fixado em 8 (CHAGAS,

Tabela 1 - Composições de bandas espectrais, índices de vegetação e componentes principais utilizadas para classificação supervisionada da imagem Rapideye.

Table 1 - Compositions of spectral bands, vegetation index and principal components used for supervised classification of Rapideye image.

\begin{tabular}{lll}
\hline 1- Total & 8 - PCA 2-NDVI & $15-$ Bandas 235-NDVI_edge \\
2- Total-NDVI & 9 - PCA 2-NDVI_edge & $16-$ Bandas 345 \\
3- Total-NDVI_edge & 10 - Bandas 234 & $17-$ Bandas345-NDVI \\
4- PCA 3 & 11 - Bandas 234-NDVI & $18-$ Bandas 345-NDVI_edge \\
5- PCA 3-NDVI & 12 - Bandas 234-NDVI_edge & $19-$ Bandas12345-PCA3-NDVI \\
6- PCA 3-NDVI_edge & 13 - Bandas 235 \\
7- PCA 2 & 14 - Bandas 235-NDVI
\end{tabular}

Total = composição de todas as bandas da imagem; PCA3 = composição das três primeiras componentes principais da imagem; PCA2 = composição das duas primeiras componentes principais da imagem; NDVI = índice de vegetação da diferença normalizada; e NDVI_edge = índice de vegetação da diferença normalizada adaptado para a banda red edge.

Revista Árvore, Viçosa-MG, v.37, n.1, p.151-161, 2013 
2006), correspondente ao número de classes temáticas de uso do solo selecionadas.

Para cada arquitetura de rede simulada, foram registrados o erro médio quadrático de teste, o erro médio quadrático de treinamento, a taxa de acurácia e o índice Kappa de treinamento. As arquiteturas das redes que apresentaram maior taxa de acurácia, menor erro médio quadrático e maior índice Kappa de treinamento foram selecionadas para avaliação da classificação (VIEIRA, 2000).

\subsection{Avaliação das imagens temáticas}

As matrizes de confusão foram geradas a partir do cruzamento de dados dos mapas temáticos com 247 pontos de validação, coletados em campo com o uso de GPS de navegação. Para realizar a coleta dos pontos de validação, dadas as dimensões geográficas do Município de Tumiritinga e a consequente dificuldade de acesso a determinados locais, realizou-se a digitalização de todas as estradas vicinais do município a partir de interpretação visual no software ArcGis 10.

Com o arquivo vetorial das estradas municipais gerado, criou-se um buffer de $200 \mathrm{~m}$ ao longo das estradas, onde foi lançada, de forma aleatória, uma malha de 250 pontos, transferidos para um aparelho GPS, que orientou o acesso ao ponto de validação e o registro da classe de uso do solo presente naquela localização. Posteriormente à coleta, foi feita a checagem para certificar se todas as classes de uso/cobertura do solo foram amostradas pela metodologia proposta.

A verificação dos erros provenientes do processo de classificação e a avaliação da exatidão dos dados obtidos pelo mapeamento temático foram realizadas utilizando coeficientes extraídos das matrizes de confusão, em especial os índices Kappa e Kappa condicional para a classe monodominância de aroeira. Ainterpretação do nível de exatidão relacionada ao valor do índice Kappa foi feita de acordo com Landis e Kock (1977).

A comparação entre os métodos de classificação e entre as composições de bandas foi realizada aplicando-se o teste estatístico z aos valores obtidos dos coeficientes Kappa e Kappa condicional para a classe aroeira, derivados da matriz de erros produzida pelo cruzamento dos resultados de cada classificação com a imagem de referência (VIEIRA, 2000).

O teste z para as os índices Kappa das classificações foi realizado a 95\% de significância. Quando $z \geq 1,96$, o teste é significativo, e rejeita-se a hipótese de nulidade, podendo concluir que existe diferença estatística entre os valores calculados (VILELA et al., 2005).

\section{RESULTADOS}

A avaliação do grau de sobreposição das amostras de treinamento pelo índice de Jefferyes-Matusita se mostrou satisfatória. Os pares de classe informacional "AM e MN" e "PM e MN" apresentaram, respectivamente, valores para o índice Jefferyes-Matusita iguais a 0,8 e 1,0 . Os valores expressam maior sobreposição de informação entre essas classes de uso do solo, tendo em vista as semelhanças espectrais dos alvos. Todos os demais pares de classe informacional apresentaram valores de índice Jefferyes-Matusita superior a 1,5.

Das 220 arquiteturas de redes neurais treinadas, a melhor apresentou a seguinte configuração: 15 neurônios em uma camada interna, taxa de aprendizado de 0,02 e 25.000 interações. O erro médio quadrático encontrado no treinamento desta arquitetura foi de 0,0018, taxa de acurácia de 91,4\% e Kappa de treinamento igual a $93 \%$.

Os valores do índice Kappa para os classificadores Maxver e RNA são apresentados na Figura 1. A classificação supervisionada utilizando Maxver alcançou valores de índice Kappa que variaram entre 62 e 80. Entre as 19 composições testadas, $84 \%$ dos resultados são interpretados como "muito bom" e $16 \%$ como "excelente" pela literatura (LANDIS; KOCK, 1977). Os melhores resultados da classificação pelo algoritmo Maxver, avaliados pelo índice Kappa, foram referentes às composições Total, PCA3-NDVI e b235-NDVI, todas com índice Kappa igual a 80.

Os índices Kappa calculados a partir das classificações por RNA variaram entre 56 e 76, sendo $11 \%$ dos resultados interpretados como "bom" e $89 \%$ como "muito bom" pela literatura (LANDIS; KOCK, 1977). Os melhores resultados da classificação por RNA, avaliados pelo índice Kappa, foram obtidos a partir das composições PCA3-NDVIe b234-NDVI_edge, ambas com índice Kappa igual a 76.

Os coeficientes Kappa das composições Total, Total-NDVI_edge, b235, b235-NDVI, b234 e b345NDVI_edge, calculados a partir da classificação Maxver, foram significativamente superiores aos coeficientes Kappa calculados a partir das RNAs pelo teste z a 95\% de probabilidade (Figura 1).

Revista Árvore, Viçosa-MG, v.37, n.1, p.151-161, 2013 
Considerando que este estudo teve por objetivo o mapeamento de áreas monodominadas pela aroeira no município de Tumiritinga, procedeu-se à análise do índice Kappa condicional da classe aroeira monodominante (AM) para definir qual o método e a composição de bandas que proporcionam a classificação e mapeamento dessas feições na paisagem de forma mais acurada.

Os coeficientes do índice Kappa condicional para a classe AM para os classificadores Maxver e RNA são apresentados na Tabela 2. Utilizando a classificação proposta por Landis e Kock (1977), para o algoritmo Maxver, 37\% das classificações são consideradas "muito boas" e 63\% são interpretadas como "excelentes" (Kappa $>80$ ). As RNAs classificaram áreas monodominadas por aroeira com desempenho das classificações "bom" (21\%), "muito bom" (58\%) e "excelente" (21\%), sendo inferiores ao algoritmo Maxver também na análise do Kappa condicional para a classe AM.

Os coeficientes Kappa condicional da classe AM das composições Total-NDVI, PCA3-NDVI_edge, PCA2NDVI_edge, b235 e b234-NDVI_edge, calculados a partir da classificação Maxver, foram significativamente superiores aos coeficientes calculados por RNAs para as referidas composições pelo teste $\mathrm{z}$ a $95 \%$ de probabilidade (Tabela 2).

Na Tabela 2, pode-se observar o efeito da utilização da banda red edge no cálculo do NDVI, avaliado pelo
Kappa condicional para a classe AM. O NDVI_edge não proporcionou melhoras significativas pelo teste z a 95\% de significância para nenhuma composição de bandas avaliadas neste estudo.

A Tabela 3 apresenta a matriz de confusão gerada a partir da tabulação cruzada entre o mapa temático produzido pela classificação da imagem Rapideye pelo algoritmo Maxver, composição Total, e os 247 pontos de validação coletados em campo com o auxílio de GPS. Cada frequência observada na matriz corresponde a uma frequência esperada. A frequência observada na diagonal apresenta a concordância entre o esperado e observado em cada categoria, ou seja, aqueles corretamente classificados. A coluna marginal representa o número total de elementos da imagem para cada classe $\left(\mathrm{X}_{\mathrm{i}+}\right)$ e a linha marginal $\left(\mathrm{X}_{+\mathrm{i}}\right)$, o número de pontos atribuídos a cada classe.

Considerando os índices de exatidão do usuário e produtor (Tabela 3), verificou-se que $93 \%$ das áreas de AM na imagem foram corretamente identificadas como AM pelo classificador, ou seja, 93\% dos pixels dessa classe foram corretamente assinalados à sua verdade de campo, e $90 \%$ da área classificada como $\mathrm{AM}$ correspondeu realmente à classe AM no mapa.

A Figura 2 apresenta o mapa das áreas sob monodominância de aroeira no Município de Tumiritinga, MG, produzido a partir da classificação supervisionada de todas as bandas da imagem Rapideye (Total), pelo

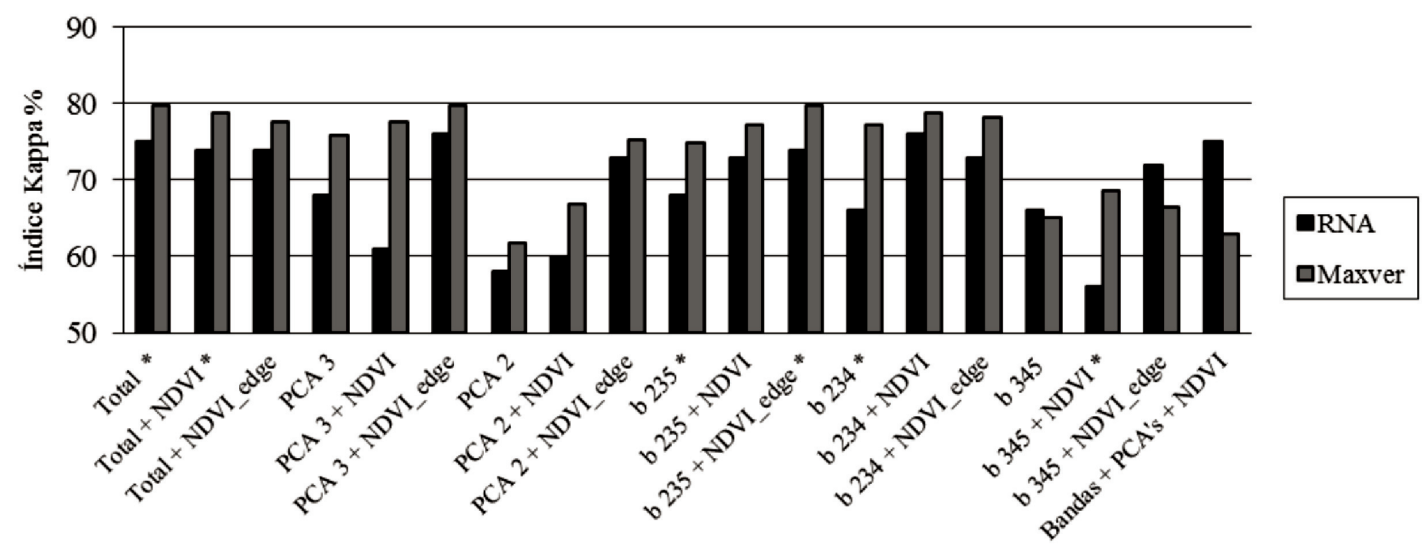

Figura 1 - Índice Kappa calculado para a classificação da imagem Rapideye pelo algoritmo Maxver e por RNA's. * no eixo, $\mathrm{x}$ indica significância estatística a $95 \%$ de probabilidade, pelo teste $\mathrm{z}$, entre os métodos RNA e Maxver.

Figure 1 - Kappa index calculated for the classification of the Rapideye image by the maximum likelihood algorithm and by artificial neural networks. ${ }^{*}$ on the $x$ axis shows statistical significance at $95 \%$ of probability by the z test between the ANN and Maxlike methods.

Revista Árvore, Viçosa-MG, v.37, n.1, p.151-161, 2013 
Tabela 2 - Índices Kappa condicional da classe Aroeira calculados a partir da classificação supervisionada pelo algoritmo da maximaverossimilhança e por redes neurais artificiais.

Table 2 - Conditional Kappa indexes for the Aroeira class calculated from the supervised classification by the maximum likelihood algorithm and artificial neural networks.

\begin{tabular}{|c|c|c|c|}
\hline Composição & Kappa Cond RNA & Kappa Cond Maxver & $\mathrm{z}$ cond \\
\hline Total & $90^{\mathrm{a}}$ & $90^{\mathrm{a}}$ & 0,00 \\
\hline Total-NDVI_edge. & $89^{\mathrm{a}}$ & $88^{\mathrm{a}}$ & 0,32 \\
\hline Total-NDVI & $67^{\mathrm{a}}$ & $86^{\mathrm{b}}$ & 2,45 \\
\hline PCA 3 & $65^{\mathrm{a}}$ & $75^{\mathrm{a}}$ & 1,18 \\
\hline PCA 3-NDVI_edge & $55^{\mathrm{a}}$ & $84^{\mathrm{b}}$ & 3,67 \\
\hline PCA 3-NDVI & $69^{\mathrm{a}}$ & $81^{\mathrm{a}}$ & 1,46 \\
\hline PCA 2 & $52^{\mathrm{a}}$ & $67^{\mathrm{a}}$ & 1,66 \\
\hline PCA 2-NDVI_edge & $53^{\mathrm{a}}$ & $90^{\mathrm{b}}$ & 4,94 \\
\hline PCA 2-NDVI & $72^{\mathrm{a}}$ & $86^{\mathrm{a}}$ & 1,85 \\
\hline b235 & $54^{\mathrm{a}}$ & $75^{\mathrm{b}}$ & 2,44 \\
\hline b235-NDVI_edge & $77^{\mathrm{a}}$ & $86^{\mathrm{a}}$ & 1,19 \\
\hline b235-NDVI & $86^{\mathrm{a}}$ & $82^{\mathrm{a}}$ & 0,56 \\
\hline b234 & $87^{\mathrm{a}}$ & $80^{\mathrm{a}}$ & 0,97 \\
\hline b234-NDVI_edge. & $69^{\mathrm{a}}$ & $80^{\mathrm{b}}$ & 1,96 \\
\hline b 234-NDVI & $79^{\mathrm{a}}$ & $84^{\mathrm{a}}$ & 0,66 \\
\hline b345 & $76^{\mathrm{a}}$ & $78^{\mathrm{a}}$ & 0,25 \\
\hline b345-NDVI_edge & $75^{\mathrm{a}}$ & $72^{\mathrm{a}}$ & 0,35 \\
\hline b345-NDVI & $77^{\mathrm{a}}$ & $72^{\mathrm{a}}$ & 0,57 \\
\hline b12345-PCA3-NDVI & $74^{\mathrm{a}}$ & $64^{\mathrm{b}}$ & 8,07 \\
\hline
\end{tabular}

$\mathrm{z}$ cond $=$ valor do teste estatístico z, a 95\% de probabilidade. Letras diferentes em linhas indicam significância a 95\% de probabilidade, pelo teste $\mathrm{z}$.

Tabela 3 - Matriz de Confusão da classificação da composição envolvendo todas as bandas multiespectrais da imagem do satélite Rapideye.

Table 3 - Confusion matrix of the composition classification involving all multispectral bands of the image of the Rapideye satellite.

\begin{tabular}{|c|c|c|c|c|c|c|c|c|c|c|}
\hline Classe & $\mathrm{RD}$ & $\mathrm{AM}$ & $\mathrm{MN}$ & SE/AU & SEA & AR & $\mathrm{PM}$ & $\mathrm{PD}$ & $X_{+i}$ & EU\% \\
\hline $\mathrm{RD}$ & 9 & 0 & 0 & 0 & 0 & 0 & 0 & 0 & 9 & 100 \\
\hline AM & 0 & 66 & 2 & 0 & 0 & 1 & 1 & 1 & 71 & 93 \\
\hline $\mathrm{MN}$ & 0 & 4 & 12 & 0 & 0 & 0 & 4 & 0 & 20 & 60 \\
\hline SE/AU & 0 & 0 & 0 & 18 & 0 & 0 & 0 & 0 & 18 & 100 \\
\hline SEA & 0 & 0 & 0 & 2 & 3 & 0 & 0 & 0 & 5 & 60 \\
\hline $\mathrm{AR}$ & 0 & 0 & 0 & 0 & 0 & 9 & 0 & 0 & 9 & 100 \\
\hline PM & 0 & 3 & 0 & 4 & 0 & 0 & 49 & 12 & 68 & 72 \\
\hline PD & 0 & 0 & 0 & 5 & 0 & 1 & 0 & 39 & 45 & 87 \\
\hline$X_{i+}$ & 9 & 73 & 14 & 30 & 3 & 11 & 54 & 52 & 247 & - \\
\hline $\mathrm{EP} \%$ & 100 & 90 & 86 & 60 & 100 & 82 & 91 & 75 & - & - \\
\hline
\end{tabular}

Em que RD = rio Doce; $\mathrm{AM}$ = aroeira monodominante; $\mathrm{MN}=$ mata nativa; $\mathrm{SE}=$ área urbana/solo exposto arenoso; as = solo exposto argiloso; $\mathrm{AR}=$ afloramento de rocha $\mathrm{PM}=$ pasto manejado $\mathrm{PD}=$ pasto degradado $; \mathrm{EP}=$ exatidão do produtor; e $\mathrm{EU}=$ exatidão do usuário .

algoritmo Maxver. A imagem temática que identifica todas as classes de uso do solo mapeadas neste estudo não pode ser apresentada por limitações de diagramação e escala. No entanto, do mapa temático produzido foi possível extrair informações a respeito da distribuição e dimensão das classes de uso de solo predominante no município de estudo.

Observou-se que cerca de $22 \%$ do Município de Tumiritinga, aproximadamente 10.158 ha, se encontrava sob a ocupação da aroeira em monodominância. As

Revista Árvore, Viçosa-MG, v.37, n.1, p.151-161, 2013 


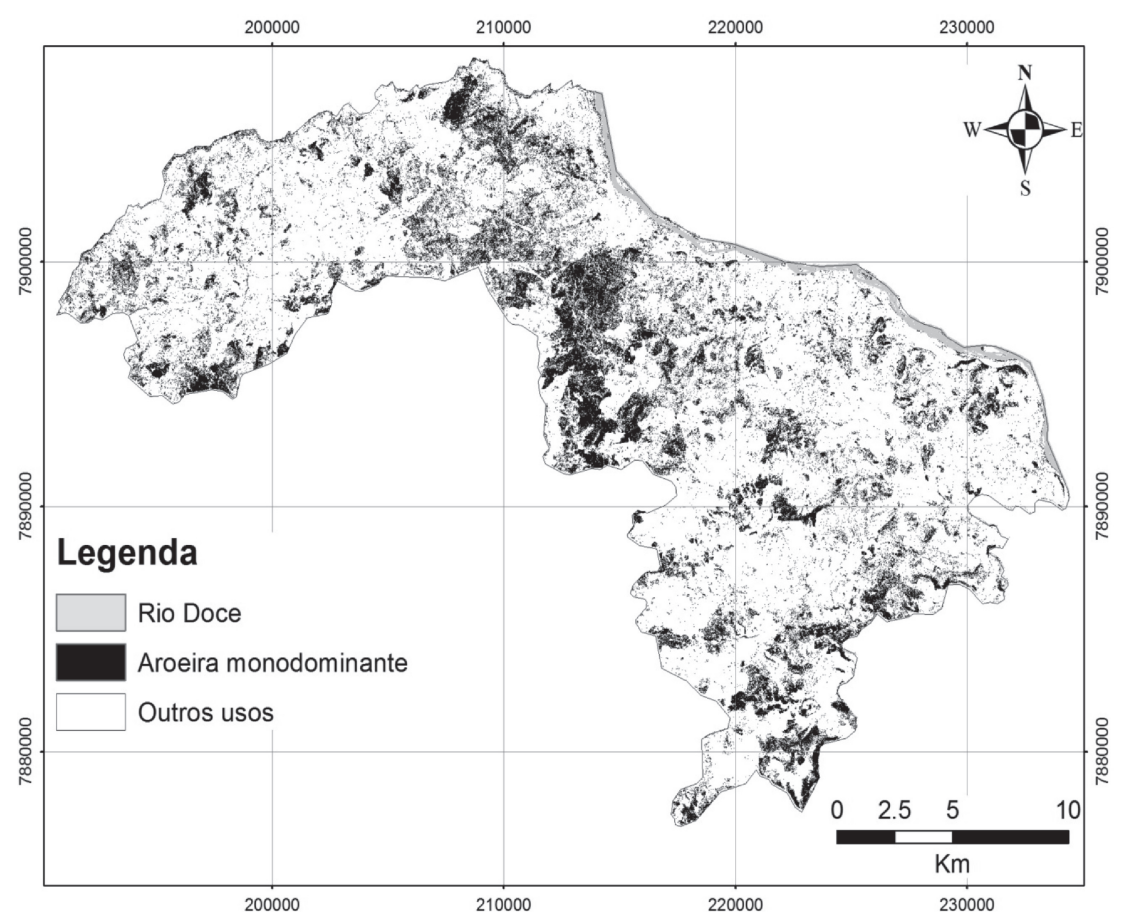

Figura 2 - Mapa temático de áreas sob monodominância de aroeira no Município de Tumiritinga, MG, produzido através da classificação supervisionada Maxver de todas as bandas multiespectrais do satélite Rapideye.

Figure 2 - Thematic maps of areas under Aroeira mono-dominance in the city of Tumiritinga, state of Minas Gerais, produced by the supervised Maxlike classification of all multispectral bands of the Rapideye satellite.

pastagens ocupavam, em conjunto, $65 \%$ do município e a área de mata nativa, uma área de 730 ha, relativa a cerca de $1,8 \%$ do território municipal.

\section{DISCUSSÃO}

A decisão de escolha do melhor classificador e da melhor composição de bandas para os dados do caso em estudo foi fundamentada pela análise de desempenho dos coeficientes Kappa e Kappa condicional para a classe AM (LANDIS; KOCK, 1977), seguidos do teste estatístico z a 95\% de significância sobre os valores dos coeficientes e suas variâncias (VILELA et al., 2005).

A tendência geral de superação do algoritmo Maxver frente às RNAs, avaliada pelo índice Kappa, permite afirmar que o algoritmo Maxver foi mais eficiente para classificar as classes de uso e ocupação do solo de Tumiritinga, MG. Das 19 combinações testadas, Maxver apresentou maiores valores de Kappa em 16 combinações, sendo seis delas significativamente superiores pelo teste z a 95\% de significância.

Revista Árvore, Viçosa-MG, v.37, n.1, p.151-161, 2013
A análise dos índices Kappa condicional para a classe "aroeira monodominante" indicou melhora na acurácia do mapeamento para a referida classe, tanto por Maxver quanto por RNAs (Tabela 2). A superação do algoritmo Maxver frente às RNAs foi mantida pela avaliação do Kappa condicional para AM, sendo a classificação pelo algoritmo Maxver significativamente superior $(\mathrm{z}>1,96)$ à classificação por RNAs em 5 das 19 combinações testadas.

Embora as redes neurais tenham alcançado, em algumas composições de bandas, resultados que não diferiram estatisticamente dos obtidos por Maxver, recomenda-se utilizar o classificador Maxver, dado seu menor custo operacional e seu melhor desempenho para o conjunto dos dados. O treinamento de RNAs demanda alto custo operacional nas etapas de préprocessamento dos dados e treinamento da rede. É importante ressaltar que o processo de seleção das amostras de treinamento é um passo fundamental para o bom desempenho do Maxver. As amostras devem 
ser coletadas de forma a representar a diversidade espectral da classe a ser mapeada.

Não foram observadas diferenças significativas entre as melhores composições classificadas pelo algoritmo Maxver. Assim, a composição de todas as bandas do satélite Rapideye (Total), é recomendada para utilização no mapeamento da monodominância de aroeira, na região de estudo, por ter apresentado os maiores valores de Kappa e Kappa condicional (Figura 1 e Tabela 2) e por condicionar maior simplicidade ao processo de classificação, visto que a imagem do satélite não precisa ser submetida a nenhum pré-processamento antes da classificação (extração de componentes principais e cálculo de índice de vegetação).

Como observado por Schuster et al. (2010), a banda red edge apresentou sensibilidade para a distinção de vegetação arbórea e arbustiva na paisagem da classificação de Maxver. No entanto, neste estudo, essa sensibilidade não produziu ganhos significativos a $95 \%$ de probabilidade pelo teste $\mathrm{z}$, sendo ainda notado efeito prejudicial aos valores dos coeficientes Kappa condicional pelas classificações por RNA.

As classes de uso do solo AM, MN e PM foram as classes que apresentaram maior sobreposição de informação espectral pelo índice Jefferyes-Matusita. Esses resultados podem ser também observados pela análise da matriz de confusão (Tabela 3), que apresenta os erros de omissão e comissão referentes às classes temáticas.

Os erros de comissão ocorrem quando se incluem pixels em uma classe quando ele pertence a outra classe, e os erros de omissão acontecem quando são atribuídos a determinada classe os erros de classificação das outras classes. Os erros de omissão em relação à classe AM (5), embora em baixa frequência, foram observados nas classes MN (2), AR (1), PM (1) e PD (1). Os erros de comissão tiveram ocorrência nas classes MN (4) e PM (3). As confusões observadas entre as classes AM, MN e PM acontecem em razão da semelhança na assinatura espectral entre elas.

Na Tabela 3, observa-se também a exatidão do usuário $(93 \%)$, que indica a probabilidade de uma categoria classificada representar a mesma categoria no campo e a exatidão do produtor $(90 \%)$, que se refere à probabilidade de determinada categoria ter sido corretamente classificada de acordo com os pontos de referência.
Os resultados podem ter sido favorecidos pela baixa ocorrência de fragmentos de mata nativa em Tumiritinga, MG. Como mata nativa e aroeira são classes que apresentam características espectrais muito semelhantes, é importante validar o método de classificação aqui proposto em regiões com maior área recoberta por outras feições florestadas.

As informações extraídas do mapa temático permitem indicar que $22 \%$ do município, 10.758 ha, estão sob a ocupação de áreas monodominadas por aroeira. O percentual de mata nativa encontrado neste estudo $(1,8 \%)$ é coerente com as informações obtidas do Censo IBGE 2010.

\section{CONCLUSÕES}

O algoritmo da máxima verossimilhança foi superior às redes neurais artificiais na grande maioria das classificações, quando avaliado pelo índice Kappa. $\mathrm{O}$ teste $\mathrm{z}$ apontou seis classificações significativamente superiores para Maxver em comparação com as RNAs.

Cinco coeficientes Kappa condicional para a classe aroeira monodominante, calculados a partir das classificações por Maxver, foram significativamente superiores aos coeficientes calculados por RNA pelo teste $\mathrm{z}$ a $95 \%$ de significância,

A classificação supervisionada da composição de todas as bandas multiespectrais do satélite Rapideye, através do algoritmo da máxima verossimilhança, foi o método selecionado para o mapeamento de fragmentos monodominados por aroeira em Tumiritinga, MG. A metodologia adotada possibilitou mapear fragmentos monodominados por aroeira com acurácia interpretada como "excelente" pela literatura.

A análise do uso e cobertura do solo em Tumiritinga não retratou, na região de estudo, o quadro anunciado de espécies ameaçadas de extinção, no qual se encontra M. urundeuva, onde os fragmentos monodominados pela espécie representam $22 \%$ da cobertura do solo do município estudado.

\section{AGRADECIMENTOS}

Ao Conselho Nacional de Desenvolvimento Científico e Tecnológico (Edital 26-2010) e à Fundação de Amparo à Pesquisa do Estado de Minas Gerais (Edital Universal 2010), pela concessão dos recursos financeiros utilizados na realização deste trabalho.

Revista Árvore, Viçosa-MG, v.37, n.1, p.151-161, 2013 


\section{REFERÊNCIAS}

AMARAL, M. V. F. et al. Avaliação e comparação de métodos de classificação de imagens de satélite para o mapeamento de estádios de sucessão florestal. Revista Árvore, v.33, n.3, p.575-582, 2009.

BARUQUI, F. M. Inter-relações solo-pastagem nas regiões Mata e Rio Doce do estado de Minas Gerais. 1982. 119f. Dissertação (Mestrado em Solos e Nutrição de Plantas) Universidade Federal de Viçosa, viçosa, MG, 1982.

BRASIL. Ministério do Meio Ambiente. Instrução Normativa $\mathrm{n}^{\circ} 06$ de 23 de setembro de 2008. Traz a lista oficial de espécies da flora brasileira ameaçadas de extinção e com deficiência de dados. Diário Oficial [da] União. Brasília: 2008.

CAMPBELL, J. B. Introduction to remote sensing. New York: The Guilford Press, 1987. 551p.

CHAGAS, C. S. Mapeamento digital de solos por correlação ambiental e redes neurais em uma bacia hidrográfica no domínio de mar de morros. 2006. 238f. Tese (Doutorado em em Solos e Nutrição de Plantas) Universidade Federal de Viçosa, Viçosa, MG, 2006.

CONGALTON, R. G. A review of assessing the accuracy of classifications of remotely sensed data. Remote Sensing Environmental, v.37, n.1, p.35-46, 1991.

COnGalton, R. G.; GREEn, K. Assessing the accuracy of remotely sensed data: principles and practices. Boca Raton: CRC Press, 1999. p. 210.

FAVERO, C. Uso e degradação dos solos na microregião de Governador Valadares Minas Gerais. 2001. 68f. Dissertação (Mestrado em em Solos e Nutrição de Plantas) - Universidade Federal de Viçosa, Viçosa, MG, 2001.

FRANÇA, M. M. Avaliação de classificações supervisionadas com redes neurais $\mathrm{e}$ maxver PR caracterização do uso da terra no município de Viçosa - MG. 2007. 66f. Dissertação (Mestrado em em Solos e Nutrição de Plantas) - Universidade Federal de Viçosa, Viçosa, MG, 2007.
HORNING, N. et al. Remote sensing for ecology and conservation. Oxford: New York, 2010. p.451.

INSTITUTO BRASILEIRO DE GEOGRAFIA E EStATÍstiCA - IBGE. Censo Demográfico. Rio de Janeiro: 2010.

INSTITUTO BRASILEIRO DE GEOGRAFIA E estatísticA - IBGE. Censo Agropecuário. Rio de Janeiro: 2006.

KAVZOGLU, T.; VIEIRA, C. A. O. An analysis of artificial neural network pruning algorithms in relation to land cover classification accuracy. In: REMOTE SENSING STUDENTS CONFERENCE, 1998, Proceedings... Oxford: 1998. p.53-58.

LANDIS, J. R.; KOCH, G. G. The measurement of observer agreement for categorical data. Biometrics, v.33, n.1, p.159-174, 1977.

MCCOY, R. M. Field methods in remote sensing. New York: The Guilford Press, 2005. p. 177 .

MOREIRA, M. A. et al. Geotecnologias para mapear lavouras de café nos estados de Minas Gerais e São Paulo. Engenharia Agrícola, v. 30, n. 6, p. 1123-1135, 2010.

MURTA, R. O.; COELHO, F. M. G.; OLIVEIRA, F. $P$. Impasses legais diante dos limites ambientais postos pela monodominância da aroeira na região do médio rio Doce/MG. In:

\section{CONGRESSO INTERNACIONAL DE DIREITO}

AMBIEnTAl, 14., 2010, São Paulo. Anais... São Paulo: 2010. p.153-162.

PRADO, R. B. et al. Mapeamento e descrição do padrão de uso e cobertura da terra em municípios do sudoeste goiano a partir de imagens orbitais TM/Landsat-5. Rio de Janeiro: Embrapa Solos, 2009. 44p.

RAMIREZ, G. M. et al. Comparação de dados dos satélites Ikonos-II e Landsat/ETM+ no estudo de áreas cafeeiras. Pesquisa Agropecuária Brasileira, v.41, n.4, p.661-666, 2010. 
SCHUSTER, C.; FORSTER, M.; KLEINSCHMIT, B. Evaluation of the RapidEye red edge channel for improving land-use classifications. In: KOHLHOFER, G.; FRANZEN, M. (Hrsg.). TAGUNGSBAND DREILÄNDERTAGUNG OVG, DGPF UND SGPF, 30., 2010, Österreich. Wissenschaftlich-Technische Jahrestagung der DGPF. Österreich: Technische Universiät Wien, 1.-3. Juli. (Band 19).

TSO, B.; MATHER, P. Classification methods for remotely sensed data. Danvers: Taylor e Francis Group, 2009. p.317.

VAlENTE, E. L. Caracterização da intensidade de degradação do solo e da cobertura vegetal de uma área no médio Rio Doce, utilizando imagens IKONOS II. 2005. $89 \mathrm{f}$. Dissertação (Mestrado em em Solos e Nutrição de Plantas) - Universidade Federal de Viçosa, Viçosa, MG, 2005.
VELOSO, H. P. et al. Classificação da vegetação brasileira, adaptada a um sistema universal. Rio de Janeiro: IBGE, 1991. 124p.

VIEIRA, J. L. Relação entre atributos do solo e ocorrência da aroeira do sertão (Myracrodruon urundeuva Freire Allemao) na RPPN fazenda Bulcão, médio Rio Doce, MG. 2008. 75f. Dissertação (Mestrado em Meio Ambiente e Sustentabilidade) - Centro Universitário de Caratinga, Caratinga, 2008.

VIEIRA, C. A. O. Accuracy of remotely sensing classification of agricultural crops: a comparative study. 2000. $323 \mathrm{f}$. Thesis (Ph. D.) - University of Nottingham, Nottingham, 2000.

VILELA, F. V. et al. Uso de imagens orbitais como base de dados para projetos de reforma agrária. Revista Árvore, v.29, n.4, p.627-638, 2005. 
